\title{
Classroom Discourse: The Role of Teachers' Instructional Practice for Promoting Student Dialogues in the Early Years Literacy Program (EYLP)
}

\author{
Bodil Stokke Olaussen
}

Department of Education, University of Oslo, Norway

Copyright $\bigcirc 2016$ by authors, all rights reserved. Authors agree that this article remains permanently open access under the terms of the Creative Commons Attribution License 4.0 International License

\begin{abstract}
Understanding that classroom discourse is important for reading comprehension and critical thinking is emerging. The aim of the present study was to analyze what teachers say and do, to promote discussion at a teacher-led station in the Early Years Literacy Program (EYLP). The EYLP is a program for reading instruction, organized at different stations. This program was chosen because a teacher-led station is the only place during the 60-minute session in which students talk with an adult. The other stations are self-instructed. We used a case study design, with video observations of two Norwegian first-grade teachers. The teaching sequences were analyzed from two theoretical perspectives: the teachers' ability to promote an "extended discourse" and the teachers" ability to use "all-purpose academic words." Extended discourse is characterized by decontextualized language use, promoting turn-taking and discussions of rare words. All-purpose academic words are abstract words adult speakers use in discussions, such as achieve, adjust, challenge etc. The results show that both teachers had positive initiations of extended discourse, but the time used for these activities was brief. Use of all-purpose academic words was scarce. How to promote classroom discourse and its consequences for students' learning is discussed.
\end{abstract}

Keywords Classroom Discourse, Extended Discourse, Vocabulary Development, Teacher Guidance

\section{Introduction}

\subsection{Background}

Experience with language during the preschool and early school years is central to later reading development and text comprehension [1,2]. A meta-analysis based on an evaluation of nine programs that foster classroom discussion concluded that these programs affect text comprehension and critical thinking [3]. Recently, Lawrence and his colleagues [4] concluded the following after an intervention study that fostered academic vocabulary skills through the classroom discussion program Word Generation: "We do not know of any prior empirical study that has established that improved classroom discussion mediates treatment effects on students word learning from a vocabulary intervention" (pp. 781-782). Reznitskaya and Gregory [5] also discussed that dialogic teaching contributes to critical thinking. However, although we know dialogic teaching fosters students' thinking and learning, this style of teaching is rare in U.S. classrooms [5]. We know that classroom discourse traditionally is characterized by teacher initiation and the students' response and ends with the teacher's evaluation (IRE) [6]. These IRE dialogues are often dominated by "closed questions," which most often request a one-word answer or a "yes/no" answer. Students are seldom encouraged to elaborate on or give a reason for their thoughts, contrary to what, Webb [7] and others $[8,9]$, for example, recommend as the most effective tool for fostering children's thinking.

In the book Exploring Talk in School, Mercer and Hodgkinson [8] brought together researchers and practitioners who shared their thoughts about how we can improve classroom talk. Hodgkinson and Mercer [9] argued "classroom talk is not merely a conduit for the sharing of information, or a means for controlling the exuberance of youth; it is the most important educational tool for guiding the development of understanding and for jointly constructing knowledge" [9, p.xi].

It seems well documented that classroom discourse is important for reading development and text comprehension, with consequences for students' learning and academic development. Despite this fact, research indicates that classroom talk seems difficult to change [5,35].This knowledge obligates us to help teachers and teacher educators improve the dialogues in school from an early age. To our knowledge, this is seldom given priority in teacher 
education [33]. Learning to implement dialogic teaching seems to present a serious challenge for teachers. Much more needs to be known about how to support teachers in promoting students dialogs [38]. From other research on teacher education $[39,40]$ we know that using theory for reflection on practice, especially on own practice, is a good way for guiding teachers. Hence it is important to isolate good practice for promoting student dialogs from an early age, good examples being useful tools for teacher guidance.

\subsection{Terminology}

The terminology in the area classroom discussion varies. Different researchers use different terms, such as classroom discussion, classroom discourse, classroom dialogue, dialogic teaching and learning, dialogic inquiry, explanatory talk [2-11] and accountable talk [20,21]. These constructs are not defined in the same way, but they are all framed in a sociocultural perspective of learning and development [12]. These somewhat different conceptualizations of classroom language have broadened and deepened our understanding of the field but also created a coordinated message from the different research groups that is more difficult for teachers to understand and incorporate in their practice [10]. Although these terms are not defined in the same way, there is emerging consensus about what makes classroom discourse productive for learning $[10,20]$. Hennessy and her colleagues [10] pointed out, "In essence, these focus on attunement to others' perspectives and continuous co-construction of knowledge through sharing, critiquing and gradually reconciling contrasting ideas" (p.16). Following Cazden [6], we use classroom discourse as our general term, but also the term dialogue, because that is what is going on in the classroom discourse, not only between teachers and students but also between students. Otherwise, as a language variation, we use the term classroom discussion. We adopted the term "extended discourse" from the Harvard group [2] and use their operationalization of this term as our analytic tool for what kind of talk is present at the teacher-led station in the Early Years Literacy Program (EYLP). We are interested in the development of discourse during the early school years, and the Harvard group used this term for understanding what is crucial to language development among young children [2]. The Harvard group's operationalization of the term elaborates on the actual processes in the development of new vocabulary, critical thinking and reasoning, and construction of knowledge.

\subsection{What is EYLP?}

The EYLP is a reading program developed in New Zealand and Australia [13], and frequently used in Norway. Norwegian teachers have been traveling 'down under' to learn, and have introduced this reading program in Norwegian schools over the last 15 years. The program is often illustrated as a puzzle of four bricks, called the structured classroom program, parent involvement, competence building for teachers and reading recovery for struggling students. All four areas are believed to have the same importance for good results. The present study focuses on the classroom program, delimitated to a teacher-led station. The teaching is organized in different stations, and the students are divided into groups of four or five children according to reading level. During a 60-minute session, the students cycle, in our case, among five stations, of which only one is teacher-led. The other four stations are self-instructed with activities, such as book reading, computer assignments, drawing/block building and writing. Each station lasts 10 to 12 minutes, with additionally a whole class introduction to the session and summing up in the end. At the teacher-led station, the students are to be taught in a flexible manner, with what they need at their level. Small booklets with pictures and drawings of varied complexity are used for the different groups. In addition to working with phonological awareness and letter knowledge, which is important in first grade, the teachers discuss what is going on in the booklets. Talk and language development are an essential part of the work at the teacher-led station. We chose this program for two reasons. First, the teacher-led station is the only place during the 60-minute session where the students interact with an adult. In this context, the teacher has rich opportunities to develop a discourse with the group and use dialogic teaching to enhance the quality of talk at this station. Therefore, we were interested in what is really going on there. Second, the EYLP emphasizes the importance of teacher guidance to enhance their competence, as well as co-work between teachers and cooperation between teachers and parents. Teacher guidance is at its best when it can be framed in research from own practice.

We based our analyses of what happened at the teacher-led station on two perspectives from international reading research: extended discourse and the use of all-purpose academic words. Both perspectives are embedded in a broader sociocultural view of learning [12] and a connection between language and literacy development, characterized as "Beginning Literacy with Language" by a group of Harvard researchers [2]. We examine what constituted extended discourse and what characterizes all-purpose academic words.

\section{Theoretical Framework}

\subsection{What is Extended Discourse?}

Different studies have shown that there is a robust relationship between children's vocabulary development and reading development $[1,2]$. When entering school, children with educated mothers and children from middle-class homes with a higher income usually have a larger vocabulary than children from low-income families. Cunningham and Stanovich's [1] study showed that children's language level and literacy skills in kindergarten and first grade are strong 
predictors of reading achievement later. In the "HomeSchool Study," the Harvard group [14] was interested in another aspect of language. They were interested in "children's experience with language that replicates some of the demands of literacy- that is, talk that requires participants to develop understandings beyond the here and now and requires the use of several utterances or turns to build a linguistic structure, such as explanations, narratives, or pretend" [14,p.2]. They called this type of talk extended discourse.

\subsection{What Characterizes the Different Kinds of Talk in Extended Discourse?}

To build an understanding beyond the concrete situation, the use of decontextualized language or nonimmediate talk is necessary. Decontextualized language refers to information that is not immediately visible, for instance, in an illustration or mentioned in the text. This type of language typically involves longer utterances and more explicit, complex language than labeling or "yes/no" questions that constitutes most immediate talk. That is why decontextualized language is a kind of extended discourse $[14,15]$. Explanatory talk is another aspect of extended discourse. It is defined "as talk that requested and/or made a logical connection between objects, events, concepts and conclusions" [16, p.86]. It is an explanation of people's actions or speech. Narrative talk or storytelling as part of extended discourse tells us about an event in the past or an event that will happen in the future [16, p.83]. Narratives may especially foster children's abstract understanding of how to organize a set of events into a story and to comprehend others' narratives. Beals [16] gave examples of how children use rhetorical questions, such as "Guess what?" to extend the narrative, conversational fillers such as "um" and retracing, such as "after school program," to compose the narrative $[16, p .84]$. Pretend talk, the last aspect of different kinds of talk connected to extended discourse, is most frequent during play. Katz [17] defined social pretend play as a situation in which "participants explicitly or implicitly make objects, people, places or other aspects of the here and now represent something other than what they are. That is, they make symbolic transformations" [17,p.56]. The motivation for pretend play lies in the experience of the activity itself.

The Home-School Study [14] concluded that the children who entered kindergarten with high-level language skills were "the children who had experienced interesting talk, with lots of new words, and literacy activities such as frequent and varied book reading with different people" [14, p.136]. Dickinson [19] reported for the kindergarten part of the study that many teachers stated that book reading was important, but few approached books in a carefully-thought-out manner. Some teachers used effective reading styles but spent little time on the activity. Other teachers spent more time reading books but failed to engage the children [19, p.201].

To build an explanation, to tell a story or to discuss a topic, conversation requires several utterances or turns to build a linguistic structure. Children must be given opportunities to gain competence in talking, expressing their meanings and providing reasoning for their thoughts. We have to ask for their opinion and use "open questions" that tell children we are interested in their thoughts and the reason for their thoughts $[18,19]$. A "yes/no" answer is not sufficient. Discourse requires participants formulate their arguments, give a reason for their argument and connect their arguments in a logical way to a conclusion. Listening to classmates' thoughts and reason for their arguments gives new perspectives. This way, discourse provides other developmental opportunities than narratives.

Discussing rare words as vocabulary development could be placed as a category alone. Our reason for considering the introduction of rare words an aspect of extended discourse is that rare words are often introduced in connection with decontextualized talk, explanatory talk or book reading. Tabors, Beals and Weizman [22] defined rare words as words that might be new words for preschool and young school-age children. These words are low frequent, concrete words. We were interested in teachers' frequent initiative to introduce and discuss words they suppose are unknown to their students, especially asking for word meaning, giving a definition or finding a synonym for the word. Tabors et al. [22] found a relationship between the frequency of use of rare words at home and kindergarten vocabulary.

Summing up, extended discourse is talk characterized by several utterances, with use of decontextualized or nonimmediate talk, to build an explanation, a narrative or pretend talk, where rare words are introduced and discussed.

\subsection{All-purpose Academic Words}

"All-purpose academic words" are difficult to define. In contrast to rare words, all-purpose academic words are abstract words used by adult speakers and in different texts. These words are not discipline-specific but are used in different topics. Examples from Coxhead's Academic Word List [23] include achieve, adjust, challenge, conclude and relevant. They are more frequently used in academic texts for older children, and therefore important for developing readers [24]. These words are usually learned by listening to people who use the words in discussion or storytelling, or through reading text in which these words are used. When children do not read much, or participate in dialogues or listen to discussions, the possibility of learning these words is reduced. Snow, Lawrence and White [24] started a project called Word Generation to promote learning of all-purpose academic vocabulary among sixth- to eight-grade students in Boston public schools. The teachers in these grades were worried about the students' low reading ability and limited text comprehension. The word learning in this project adhered to research-based principles of vocabulary learning. The students were taught five new words every week, and these words were used in texts, classroom discussion and 
writing assignments in different topics, such as English arts, math and science. Discussion topics were designed around issues of interest for this age group. In this way, the program provided opportunities to develop a deeper understanding of the words through practicing them in different topics. The study results were promising. The students who participated in the project learned more of the targeted words than students in the comparison schools, and the quality of the discussion in the treatment classrooms was remarkably higher than in the control classrooms. Students whose native language was not English benefited more than English-only students. A longitudinal follow-up study of the Word Generation program showed that the differences lasted at least 1 year [25]. This study also documented that word learning was mediated through classroom discussion [4]. Based on these results, it is important that teachers are aware of this special type of words and stimulate children from an early age in school, to prepare them for the growing complexity of the text with which they are presented.

\section{Research Questions}

Knowing that the quality of the discourse in which students participate is important for reading development, text comprehension and critical thinking, we were interested in what teachers say and do to promote discourse, especially extended discourse, at the teacher-led station in the EYLP. At this station, the teacher talks with the students about booklets and has the possibility of using decontextualized language, encouraging turn-taking, talking about rare words and introducing all-purpose academic words during the session.

The questions asked were as follows:

1. How do teachers initiate extended discourse at the teacher-led station during the EYLP?

a. to foster decontextualized language?

b. to encourage children to take turn and participate in the dialogues?

c. to develop an understanding of rare words?

2. Is extended discourse representative for what is going on at teacher-led station?

3. What kind of all-purpose academic words are used, and how frequently are these words used?

\section{Design, Materials and Methods}

We used a case study design [26], with two Norwegian teachers in first grade as the cases. It was a video-based observation study, with qualitative and quantitative analyses. For judging the design quality, we followed Yin's validity criteria [26, p.45].

\subsection{Sample}

This study was part of a larger study, in which we followed five teachers in first and second grade in the same school over three days teaching all five student groups in their class at the teacher-led station in the EYLP. The two cases in this study taught first grade, and the three other teachers taught second grade. Participation in the study was voluntary. The parents of all the students were asked if their children were allowed to participate in the videos.

Both first-grade teachers, two women, were well educated, had an equal amount of experience and were about the same age. The teachers prepared their lessons together. Each class was divided into five groups of four or five students based on their reading level. We chose to analyze the teaching of the two student groups at the best and second-best reading levels in both classrooms. The communication between the teachers and the students seemed to be richest in these groups, and the booklets had the same complexity. Although the research focused on what teachers said and did, the students' responses contributed to the interaction in important ways, and must be taken into account in analyzing the dialogues [10].

\subsection{Data Collection and Materials}

Two researchers were present in the classroom: One operated the video camera, and one took field notes. The camera was placed in a corner and was directed from a computer. The technical tools were always set up before the students entered the room. The teachers wore a wireless microphone in order to get good acoustic quality of the talk going on. The materials used at the teacher-led station were booklets originally developed for work in Australian and New Zealand schools, translated into Norwegian. The text was very short, illustrated with pictures and drawings. The booklets varied in complexity adjusted for reading level. To match the groups and the material, we analyzed the two groups with the best and next best reading levels in both classrooms.

\subsection{Analyzed Sequences}

We analyzed the teachers' teaching of the two groups with the best reading level in their classes, and used the two days of data collection with the best match for similar activities. This means a total of eight analyzed sequences ( 2 teacher $\mathrm{x} 2$ groups $\times 2$ days $=8$ sequences). For comparison, each analyzed sequence was set to 10 minutes with the richest communication at the teacher-led station. Each teacher's initiatives were analyzed during four sequences for 10 minutes per group, which means 40 minutes per teacher. In sum, 80 minutes of teaching were analyzed for the present study. All sequences focused on talking about letters, the story in the booklets and reading the booklets. The students had the booklets with them at home before the lesson at the teacher-led station and should have read the books with their parents. 


\subsection{Analyzed Categories}

For extended discourse, we emphasized the teachers' decontextualized language use. Discourse based on booklets is a good situation in which to introduce non-immediate talk. The text in the booklets is very limited; therefore, to elaborate on the story, talk not mentioned in the text is necessary. Explanations and narratives about the pictures are naturally a kind of talk that is often characterized by decontextualized language because of the limited text and illustrations in the material. Teachers' initiation of turn-taking, to encourage students to elaborate on their own thoughts, is another category under extended discourse. The category rare words, characterized by the teachers' initiative to introduce and explain such words, to ask for interpretations or discuss their meaning with the students, is the third category of extended discourse. We placed rare words as an aspect of extended discourse, because rare words often occur during decontextualized discourse of aspects introduced in books. The last analysis category is teachers' use of and introduction to all-purpose academic words. We had Coxhead's Academic Word List [23] as our guide for isolating the words. They are all abstract words used by adult speakers and in different academic texts. To secure construct validity, we developed a codebook with examples in Norwegian for the categories we wanted to use in our analysis, with examples of decontextualized language, turn-taking, rare words and all-purpose academic words [28]. Two independent coders were used. When disagreement occurred between the coders, the examples were discussed and recoded until agreement of $\mathrm{r}=.80$ was reached to secure interrater reliability.

\subsection{Analyzing Strategies: Validity}

To answer research question 1 (RQ1), how teachers initiate extended discourse at a teacher-led station, the data were transcribed and analyzed in a qualitative way. We searched for excerpts in the dialogues between teachers and students in which the teachers used decontextualized language, initiation of turn-taking and introduction to rare words. To answer research question 2 (RQ2), whether extended discourse is representative of what is going on in the analyzed sequences, we quantified the teachers' activities using Videograph [27], a program in which what is said and done can be coded along a timeline and analyzed in frequencies of time used for different purposes. Videograph is also used to compare teachers' activities in different sequences and to compare the teachers with each other. Yin's strategy pattern matching is used to compare the teachers' activities in different sequences with themselves and to compare the two teachers [26, p.143]. The same strategy was used for judging internal validity, discussed by Yin as making inferences in qualitative studies. To secure external validity, which in case study research is an analytic generalization back to theory $[26, p .40]$, we used replication to judge similarities and differences between the two cases.
To answer research question 3 (RQ3), about the use of all-purpose academic words, we planned to use Videograph frequency analysis.

\section{Results}

The results are presented according to the three research questions. We give examples from each teacher in each main category from the qualitative analyses of extended discourse.

\subsection{Initiation of Extended Discourse (RQ1)}

On the positive side, the qualitative analyses of dialogues at the teacher-led station showed that both teachers initiated extended discourse (RQ1). They expanded the text in the booklets using decontextualized language, for instance, asking for reasons for utterances and words used. We present examples from the use of decontextualized language, introduction to rare words and initiation of turn-taking.

\subsubsection{Decontextualized Language Use}

Use of decontextualized language was initiated when teacher 1 (T1) introduced a new booklet called "Smile...Said Daddy" [29], starting with a look at the cover picture. It shows a woman, three children and a dog against a blue background. The teacher started with a relatively open question:

\section{Extract 1}

T1: What do you see here?

S1: It is a family on the beach.

T1: Why do you think it is a family?

S1: Because I think this must be a mom, and this must be a child because she is holding it, and they are together, and then it is often a family.

T1: Why do you think they are on a beach?

S1: Because it looks like sand and water in the background.

The student introduced the words "beach" and "family." These words are not mentioned in the booklet. The teacher takes the opportunity to ask the student for a reason for her word use. The teacher asked for an explanation: "Why do you think...?" Discussions about word meaning are often embedded in decontextualized language use, so it is difficult to separate decontextualized language use from the discussion of vocabulary. We have chosen to present these utterances under decontextualized language, because the discussion concerns topics that are not mentioned in the text.

Talking about the booklet "Ready, steady, jump!" [30], which tells a story about a spider, teacher 2 (T2) asked the following:

Extract 2

T2: Who do you think has taken the picture of the spider?

S1: The one who has written the book.

T2: Yes, perhaps ... but how has he managed to come 
so close?

S2: Oh, he has been zooming.

T2: Yes! He has been zooming.

The story about the spiders' jump and spin activity was interesting in itself, but the teacher expanded the talk beyond what is mentioned in the text. One student used a word that is rare for the age group, "zooming," and the teacher took the opportunity to discuss that word.

\subsubsection{Introducing Rare Words (RQ1)}

The dialogue between the teacher and students about the spider and the photography continued:

Extract 3

T2: What does it mean to zoom?

$\mathrm{S} 1$ and S2: It's to see things very close!

T2: To see things very close- Yes!

T2: But what do we use when we are zooming?

The teacher asked for a definition or an explanation of the word zooming and used vocabulary beyond what is present in the booklet to develop a deeper understanding of the word. She was connecting the discussion of the word to the tool we use for zooming.

Teacher 1 (T1) introduced a new book by asking for the title of the booklet the group would use that day and continued:

Extract 4

T1: What does the title tell us?

S1: It tells us in a way the name of the book.

T1: Mm, and perhaps what the book is about.

First, the teacher asked for an explanation of the word "title" but used the word "tell." Tell is perhaps an easier word than explain. The student's answer was not seen as sufficient, and the teacher extended it.

As we can see, both teachers asked their students for explanations of a rare word and to give a reason for their thoughts.

\subsubsection{Encouraging Turn-Taking (RQ1)}

When the students were invited to take turns in the dialogue, they were expected to articulate their opinion about a topic in such a way that their classmates could understand it. The teachers occasionally used open questions, reformulations of questions and repetition of utterances as techniques to involve more students in the dialogue. Talking about "Old Tuartara" [31], teacher 2 used different techniques to get more students involved:

Extract 5

T2: Can you guess what this might be?

S1: A toad!

T2: You think it is a toad. What do you think? (To another student)

S2: A lizard.

T2: You think it is a lizard. And you?

S5: Who is it?

Teacher 2 invited the children to participate in the dialogue by repeating the question and other utterances over several sequences. The repetition of "What do you think?" showed real interest from the teacher in each student's opinion and motivated the students to share their thoughts. Student 5 (S5) got impatient and wanted to know who old Tuartara really was.

Teacher 1 used repetition to get the students to participate in talk about the booklet "I Ride a Bike" [32]:

Extract 6

T1: When was she riding the bike? Did she ride every day or only some days?

S1: Every day

T1: Every day? Do you remember...?

S2: More and more every day.

T1: Do you remember which days it was?

S3: Monday, Tuesday, Wednesday and Saturday and Sunday.

T1: Sunday too?

Teacher 1 seemed to be repeating utterances in the first place to catch the students' attention. Afterward, she repeated and asked for more information from different students in the group.

To sum up, we find examples of the initiation of extended discourse from both teachers. They encouraged their students with decontextualized language use and discussion of rare words to participate in classroom talk. They also tried to include them in classroom talk, for instance by asking them to give explanations for their opinions.

\subsection{Is Extended Discourse representative for the Activities at the Teacher-Led Station? (RQ2)}

To look at how representative extended discourse was at the teacher-led station, we summed the time for the coded frequencies of the three different categories and compared the results for each teacher individually and with each other. This individual pattern matching of the teacher's activities concerning the coding categories showed high stability of extended discourse over the two analyzed days. The difference between the two teachers, however, is remarkable. The results are presented in Figure 1. The time used for decontextualized language, turn-taking and introduction to rare words was summed up for every analyzed sequence for each teacher (40 minutes per teacher) and presented in the figure. 


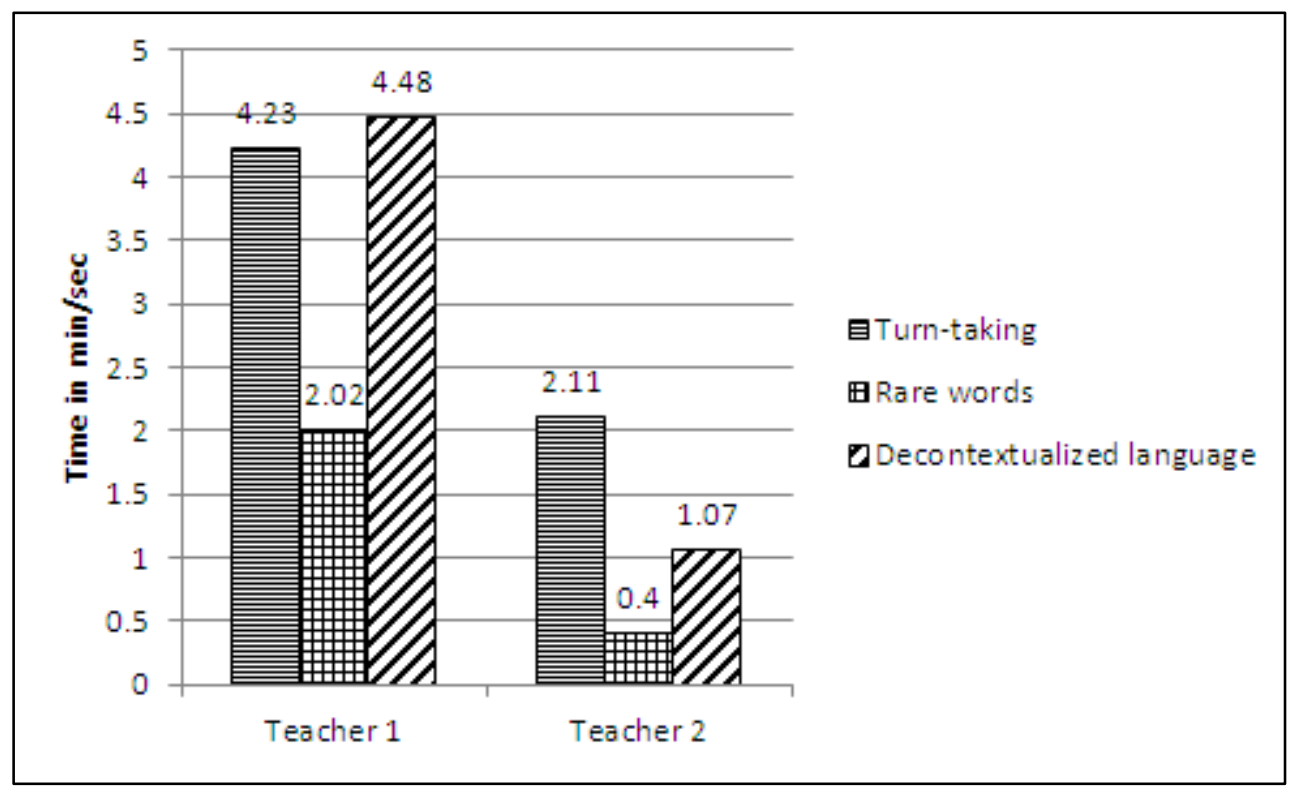

Figure 1. Frequencies of time used for extended discourse at the teacher-led station for both cases

Although the two teachers had planned their teaching sequences together, and they were asked to do what they had planned to do, the difference in the teachers' interactions with the students and initiation of different aspects of extended discourse is great. Both teachers used very little time for development of rare words, only 4 seconds of 40 minutes of teaching time by teacher 2 . In addition, the time used for decontextualized language differed. We must conclude that the time used for extended discourse was low for both cases, and extended discourse was not representative of what was going on at the teacher-led station in the sequences we observed. However, there were some really good initiatives.

\subsection{Use of All-purpose Academic Words (RQ3)}

Our search for teachers' use of all-purpose academic words (RQ3) was not successful. These kinds of words were scarce. We found some examples, such as "think," "mean" and "believe," but they are not found in the Coxhead List [23]. These words are abstract but cannot be characterized as academic words. They are more common abstract words and understood by most children. Therefore, we did not conduct any frequency analysis for answering question 3 .

\subsection{What is going on During the Rest of the Time?}

When such a small part of the time at the teacher-led station was categorized as extended discourse, what was going on during the rest of the time? Ten to 12 minutes at the teacher-led station was the only period during the 60-minute session when the students communicated with an adult. At the other stations, the students worked individually with different assignments. The teacher-led station, therefore, was important for student learning. We decided to look for dialogues in a broader perspective by including traditional IRE dialogues with Initiation, Response and Evaluation as described by Cazden [6], which is known to dominate classroom talk. In addition, we wanted to look at the time used for decoding and phonological activities, which are important issues in first grade. The results are shown in Figure 2.

Teacher 1 used half of the time at the teacher-led station for dialogues in a broader perspective, summed up for extended discourse and IRE dialogues. Nearly 9 minutes of the 40 minutes of teaching time were used for decoding exercises. Pattern matching between the two teachers showed another picture for teacher 2. Compared with teacher 1 , teacher 2 used only one fourth of teacher 1's time for dialogues, but when it came to decoding activities, she used nearly twice as much time for these activities as her colleague. There were no special differences between the children in the two teachers' groups that could provide a reason for this difference in instruction. It seems to be a difference between the cases' teaching styles. 


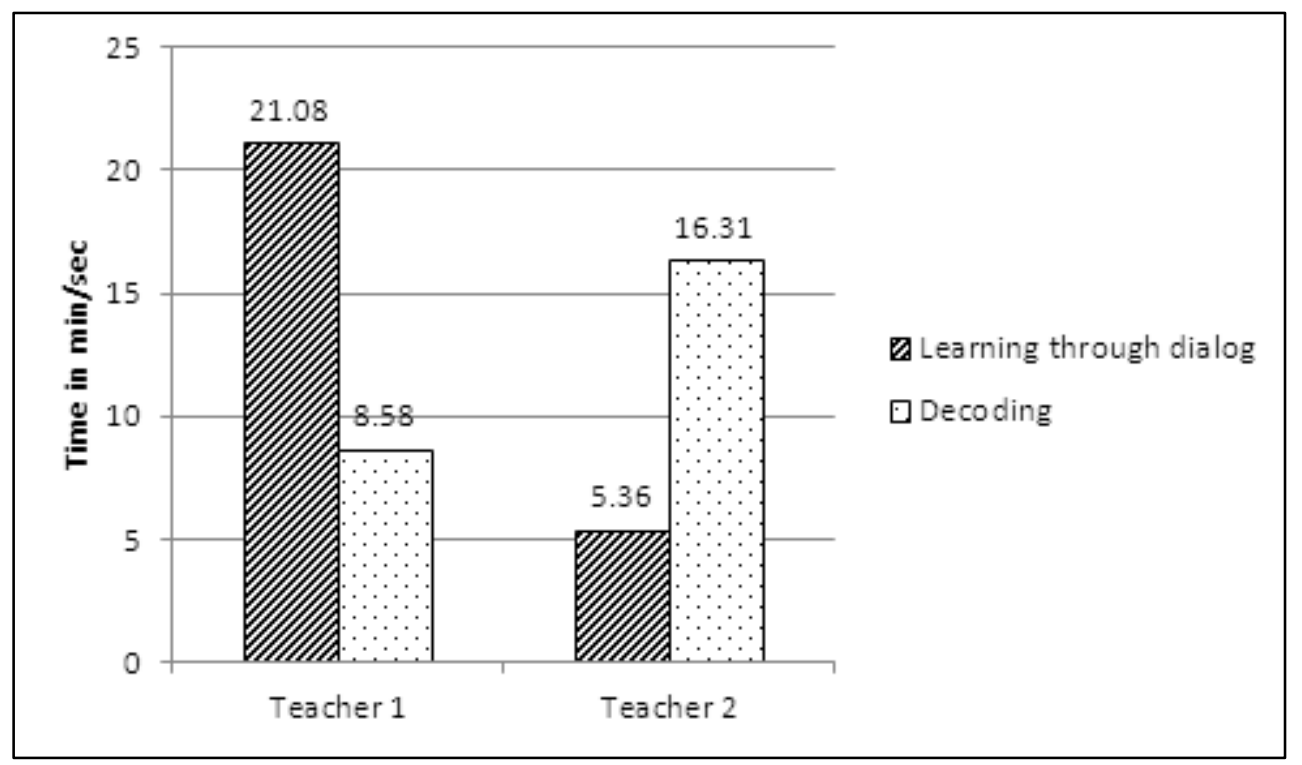

Figure 2. Summed up time used for learning through dialogues (extended discourse and IRE) and decoding exercises at teacher-led station

\subsection{Loss of "golden moments"}

Another interesting thing we observed was the teachers' awareness of initiatives from the students that could lead to extended discourse. Some initiatives were invited, and the students were encouraged to elaborate on them, as in extract 2 , but other initiatives with really golden opportunities for discourse in the groups got lost. In the dialogue about "Old Tuartara" [31], one student wanted to tell more about the toad:

Extract 7.

S4: This is a toad

$\mathrm{T}$ : Yes

S3: I think it is that big (shows with his hands)

$\mathrm{T}$ : Do you think it is that big?

S3: Yes!

S4: Shall I tell you, if you are holding a toad, it will lose its tail!

S3:Yes!

$\mathrm{T}$ : (wondering) Is it really true?

Does the toad lose its tail when you are holding it?

S4: Yes! When you are holding it in its tail!

S3: Yes! If you are holding it, it will lose its tail.

S4: Yes!

$\mathrm{T}$ : Yes, now we turn to the next page, page two, the number 2 .

Students 3 and 4 introduced a new perspective into the talk about the toad, new knowledge that was not present in the booklet about "Old Tuartara." They were very eager to discuss the topic, which was really interesting to the group. The teacher seemed a little surprised about the consequences of holding the toad's tail and left it with the comment, "We turn to the next page."

We saw different examples of 'golden moments' that were lost in our observations. If we as teachers meet questions or topics about which our knowledge is insufficient, that should not be a problem. Facts can be checked afterward. Being aware of what is interesting to the children, and asking them to elaborate and give a reason for their thoughts, can be a key to extended discourse in which different children take turns and supplement each other with what they know. In this extract the teacher had the opportunity to encourage the discussion between the two children, which we know is important for learning [7].

We have decided to focus on dialogs fostering development of classroom talk, therefore extract 7 is the only example with a negative end.

\section{Discussion}

The results for the limited time used for extended discourse are in agreement with what we know from previous international research $[5,6]$. The same can be said about teachers' use of all-purpose academic words [4]. A developing classroom discourse is missing not only in elementary schools; it is also the case at other school levels. In an observational study, Appleby, Langer, Nystrand and Gamoran [35] found that only 1.7 minutes per 60-minute class in middle and high school English classrooms were used for dialogic discussions. The number of minutes used for classroom discourse in the different studies is not directly comparable, since different codes and scoring systems were used. The intention to report time use has been to focus the possibility of improvement of classroom talk from a time perspective. When it comes to the use of "all-purpose academic words," the awareness of students failing knowledge of these words, and how they can be taught, is scarce among the group of teachers we observed, confirming the results of previous studies [24]. It is important to 
introduce this knowledge to student teachers and practicing teachers. Classroom discourse is not only important for improving work at the teacher-led station in the EYLP but for teaching as such.

\subsection{Teacher Differences}

Our two cases had planned their teaching together, including what to do and defining a goal for their lessons. They were using comparable booklets, and had children with the same reading levels. We know that teachers make a difference in the classroom, but the difference in the dialogic pattern used by the two cases was surprisingly great. The teaching styles concerning use of dialogs, were first compared with own teaching in the different groups the different days using Yins [26] strategy pattern matching, to see if their style varied or if each of them had a more stable trend. The check of the individual dialogic style showed a stable pattern, while the comparison between the two showed great differences (see 5.2, 5.4). The comparison was checked the same way with pattern matching. The validity of the results therefore seems trustable. Over time it is reasonable to assume that learning possibilities and development of reading comprehension will differ for these student groups because of the difference in quality of promoting student dialogs by their teacher.

\subsection{Implications for Practice}

Our knowledge of what kind of classroom talk fosters children's development of language, critical thinking and comprehension does not seem to be well-known by teachers. Discussion does not seem to be a skill prioritized in teacher education [33]. Student teachers must be made aware of the positive consequences of discourse in the classroom and how to promote it. Critical thinking and text comprehension make a difference for learning in school, and we know that proper discussions in the classroom foster these developments [3].

We know from researchers, such as Cunningham and Stanovich [1], and the Harvard group [2] that experiences at home and in preschool with the use of decontextualized language, invitation to participate in dialogues and articulate own meaning are very important for later success in school. Well-educated and knowledgeable school teachers can make a difference [4]. Michaels et al.'s [20,21] work with teachers showed that only making teachers aware of the effect of open questions really made a difference in encouraging students to participate in dialogues. Lawrence and his colleagues [4] conducted a short course for teachers as an introduction to their intervention study Word Generation, and teachers improved their practice quickly when they got to know what to do and how to do it, and had a good reason to change. Teachers' improvement of their practice after a short introduction course was also observed by other researchers, for instance, Reeve's work on improving teachers' motivation style [37].

Teachers must be made aware of the effect of inviting students to a discussion with "open questions" [20,21] in a way that makes it possible to introduce decontextualized language. Teachers must leave the traditional classroom talk with the initiation of a question, wait for a response from the students and end the dialogue with an evaluation of the answer as right or wrong. They have to ask the students to give a reason for their thoughts about what is happening, where one-word answers are not sufficient. They have to be made aware of the necessity of giving explanations for events and including students' opinions of different events for further discussion. Vocabulary development is important, and international scholars, such as Biemiller and Boote [36], concluded after many studies that schools do not work systematically enough with vocabulary development to close the vocabulary gap with which some students enter school. Rare words and all-purpose academic words are important areas of improvement. Snow et al.'s [24] innovation study with all-purpose academic words gave positive results. Teachers seem eager to change when we as researchers give them adequate information about how to develop their practice $[4,37]$. Facilitating teachers' learning with positive examples from their own classrooms is a good start. Wilkinson and his colleagues [38] point to the fact that much more needs to be known about how to support teachers in learning to conduct classroom discussion that promotes reading comprehension. We have seen beautiful examples of fostering dialogues that can give stimulation for change, and that teachers do foster children in a good way without knowing it. Combining good examples with reflection on the theory behind is a way to make teachers aware of what actually is going on. Following Hattie [39] and Robinson [40] this will stimulate teachers' use of the very best part in their practice.

\subsection{Limitation and Future Research}

Our study is a case study with two teachers. Therefore, it has clear limitations, for instance, concerning statistical generalizations. A case study research is useful for what Yin [26] called an analytic generalization, which means an analytic view of theory. The question is, whether the theory used gives a knowledgeable understanding of the data. We followed our cases in a limited time perspective, two days with work in two different groups. Despite the fact that 40 minutes teaching per teacher were analyzed, there will always be possibilities for influence of the interactions between students and teacher that is out of our range of understanding.

It would be interesting to start an innovation project to improve classroom discourse at a teacher-led station in the EYLP. We state the hypothesis that a short course in which teachers are made aware of and reflect on what is mostly going on and how their teaching can be improved, would increase the quality of their work. We have much knowledge about how classroom talk can be fostered and some knowledge of the consequences for children's learning.

As Hodgkinson and Mercer [9] reminded us: "classroom 
talk ... is the most important educational tool for guiding the development of understanding and for jointly constructing knowledge" [9, p.xi].

\section{Conclusions}

As shown in the qualitative analyses both teachers showed positive initiation of extended discourse at the teacher-led station in the EYLP. They fostered students through decontextualized language use, by introducing rare words and asking students to explain their use of these words, and to take turn in the dialogues. Evaluating how representative extended discourse is for what is happening at a teacher-led station through quantitative frequencies, we conclude that extended discourse was not a trend but occurred occasionally. The use of all-purpose academic words was scarce. Making teachers aware of the very best in their practice through good examples, reflecting together on the theoretical frame for what is going on, may incite change. Students deserve to get the opportunity to be fostered through dialogic teaching from an early age in school.

\section{REFERENCES}

[1] A. E. Cunningham, K. E. Stanovich. Early reading acquisition and its relation to reading experience and ability 10 years later, Developmental Psychology, Vol.33, No.6, 934-945, 1997.

[2] D. K. Dickinson, P. O. Tabors (Eds.). Beginning Literacy with Language, Paul Brookers, Baltimore, 2001.

[3] P. K. Murphy, I. A. G. Wilkinson, A. O. Soter, M. N. Hennessey, J. F. Alexander. Examining the effects of classroom discussion on students' comprehension of text: A meta-analysis, Journal of Educational Psychology, Vol.101, No.3, 740-764, 2009.

[4] J. F. Lawrence, A. C. Crosson, E. J. Paré-Blagoev, C. E. Snow. Word generation randomized trial: Discussion mediates the impact of program treatment on academic word learning, American Educational Research Journal, Vol.52, No.4, 705-786, 2015.

[5] A. Reznitskaya, M. Gregory. Student Thought and classroom language: Examining the mechanisms of change in dialogic teaching, Educational Psychologist, Vol.48, No.2, 114-133, 2013.

[6] C. Cazden. Classroom Discourse. The Language of Teaching and Learning, Heinemann, Portsmouth, 2001.

[7] N. M. Webb. The teacher's role in promoting collaborative dialogue in the classroom, British Journal of Educational Psychology, Vol.79,no.1, 1-28, 2009.

[8] N. Mercer, S. Hodgkinson, (Eds.). Exploring Talk in School, Sage, London, 2009.

[9] S. Hodgkinson, N. Mercer. Introduction. In N. Mercer \& S. Hodgkinson (Eds.), Exploring Talk in School, Sage, London, 2008.
[10] S. Hennessy, S. Rojas-Dummond, R. Higham, A.M. Márquez, F. Maine, R. M. Rios, R. Garcia-Carrion, O. Torreblanca, M. J. Barrera. Developing a coding schema for analysing classroom dialogue across educational contexts, Learning, Culture and Social Interaction, Vol.9, No.1, 16-44, 2016.

[11] K. Littleton, N. Mercer. Interthinking: Putting Talk to Work, Abingdon: Routledge, 2013.

[12] L. S. Vygotsky. Mind in Society: The Development of Higher Psychological Processes, Harvard University Press, Cambridge, 1978.

[13] C. A. Crevola, P. W. Hill. Evaluation of a whole-school program approach to prevention and intervention in Early Literacy, Journal of Education for Students Placed at Risk, Vol.3, 133-157, 1998.

[14] C. E. Snow, P. O. Tabors, D. Dickinson. Language development in the preschool years. In D. K. Dickinson \& P. O. Tabors (Eds.), Beginning Literacy with Language, Paul Brookers, Baltimore, 2001.

[15] J. M. Detemple. Parents and children reading book together. In D. K. Dickinson \& P. O. Tabors (Eds.), Beginning Literacy with Language, Paul Brookers, Baltimore, 2001.

[16] D. E. Beals. Eating and reading: Links between family conversations with preschoolers and later language and literacy. In D. K. Dickinson \& P. O. Tabors (Eds.), Beginning Literacy with Language, Paul Brookers, Baltimore, 2001.

[17] J. R. Katz. Playing at home: The talk of pretend play. In D. K. Dickinson \& P. O. Tabors (Eds.), Beginning Literacy with Language, Paul Brookers, Baltimore, 2001.

[18] P. O. Tabors, K. A. Roach, C. E. Snow. Home language and literacy environment: Final results. In D. K. Dickinson \& P. O. Tabors (Eds.), Beginning Literacy with Language, Paul Brookers, Baltimore, 2001.

[19] D. K. Dickinson. Book reading in preschool classrooms: Is recommended practice common? In D. K. Dickinson \& P. O. Tabors (Eds.), Beginning Literacy with Language, Paul Brookers, Baltimore, 2001.

[20] S. Michaels, C. O’Connor. Conceptualizing talk moves as tools: Leveraging professional development work teachers to advance empirical studies of academically productive talk. Socializing intelligence through talk and dialogue. In L. Resnick, C. Asterhan, S. N. Clark (Eds.), Socializing Intelligence Through Academic Talk and Dialogue, AERA, Washington DC, 2016.

[21] S. Michaels, C O'Connor, L. B. Resnick. Deliberative discourse idealized and realized: Accountable talk in the classroom and in civic life, Studies in Philosophy and Education, Vol.27, 283-297, 2008.

[22] P. O. Tabors, D. E. Beals, Z. O. Weizman. "You know what oxygen is?": Learning new words at home. In D. K. Dickinson \& P. O. Tabors (Eds.), Beginning Literacy with Language, Paul Brookers, Baltimore, 2001.

[23] Academic word list Coxhead, 2000. UefAP. Online available from http://www.uefap.com/vocab/select/awl.htm

[24] C. E. Snow, J. F. Lawrence, C. White. Generating knowledge of academic language among urban middle school students, Journal of Research on Educational Effectiveness, Vol.2, No.4, 325-344, 2009. 
[25] J. F. Lawrence, L. Capotosto, L. Branum-Martin, C. White. Language proficiency, home- language status, and English vocabulary development: A longitudinal follow - up of the Word Generation program, Bilingualism: Language and Cognition, Vol.15, No.3, 437-451, 2012.

[26] R. K. Yin. Case Study Research. Design and Methods, Sage, Los Angeles, 2014.

[27] R. Rimmele. The software Videograph. IPN, University in Kiel, 2002, Online available from http://www.ipn.uni-kiel.de

[28] A. S. Blomseth. Kategorier for analyse av dialogen på lærerledet stasjon i Early Years Literacy Program (Categories for analyzing dialogs at teacher-led station in Early Years Literacy Program). University of Oslo, 2012.

[29] "Smile! ...Said Daddy." Learning Media, Cappelen, Oslo, 2003.

[30] “Ready, Steady, Jump!” Learning Media, Cappelen, Oslo 2003.

[31] “Old Tuartara”. Learning Media, Cappelen, Oslo, 2003.

[32] “I Ride a Bike!” Learning Media, Cappelen, Oslo, 2003.

[33] C. E. Snow. Learning from talking: The importance of discussion as a source of knowledge from kindergarten through secondary school. Lecture at the University of Oslo, 2011.

[34] P. O. Tabors, C. E. Snow, D. K. Dickinson. Homes and schools together: Supporting language and literacy development. In D. K. Dickinson \& P. O. Tabors (Eds.), Beginning Literacy with Language, Paul Brookers, Baltimore, 2001.

[35] A. N. Applebee, J. A. Langer, M. Nystrand, A. Gamoran. Discussion-based approaches to developing understanding: Classroom instruction and student performance in middle and high school English, American Educational Research Journal, Vol. 40, No. 3, 685-730, 2003.

[36] A. Biemiller, C. Boote. An effective method for building meaning vocabulary in primary grades, Journal of Educational Psychology, Vol.98, No.1, 44-62, 2006.

[37] J. Reeve, Y. L. Su. Teacher motivation. In M. Gagne (Ed.), The Oxford Handbook of Work Engagement, Motivation, and Self-Determination Theory, Oxford University Press, Oxford, 2014.

[38] I.A.G.Wilkinsom, P.K. Murphy, S.Binici. Dialogue-intensive pedagogies for promoting reading comprehension: What we know, what we need to know. In L.B.Resnick, C.S.C.Asterhan, \& S.N. Clarke (Eds.), Socializing Intelligence through academic talk and dialogue. American Educational Research Association. The AERA Books Editorial Board, 2015.

[39] J. Hattie. Visible learning. A synthesis of over 800 meta-analysis relating to achievement. Routledge, London, 2009.

[40] V.Robinson. Student-Centered Leadership. Jossey-Bass Leadership Library in Education, 2011. 